\title{
クロコオロギの行動選択機構のモデリングに関する研究 一行動選択モデルの掃引作業への応用の検討一
}

\author{
Study on cricket's neuronal modeling for behavior selection \\ - Examination of application to sweeping task of behavior selection model -

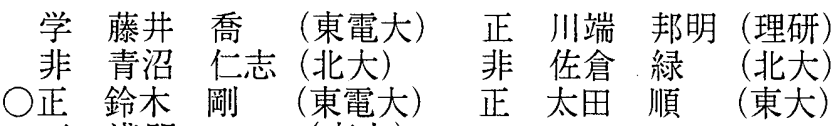 \\ 正 淺間 一 (東大)
}

Takashi FUJII, Tokyo Denki Univ.

Kuniaki KAWABATA, RIKEN,

Hitoshi AONUMA, Hokkaido Univ.,

Midori SAKURA, Hokkaido Univ.,

Tsuyoshi SUZUKI, Tokyo Denki Univ.,

Jun OTA, The Univ. of Tokyo,

Hajime ASAMA, The Univ. of Tokyo

\begin{abstract}
An insect generates an environmental adaptive behavior by a small brain. The authors think that such ability for environmental adaptation brings useful knowledge for behavior control of a multi-robot system. Therefore, ability for environmental adaptation of a cricket was modeled as a behavior selection model. Such ability for environmental adaptation of insects is not yet elucidated enough. Therefore, in this study, the authors discuss about an engineering application of proposed cricket's behavior selection model. In particular about this paper, proposed model was discussed and compared with other behavior selection model efficiency as an example in sweeping task.
\end{abstract}

Key Words: Cricket fighting behavior, Mobiligence, Social adaptation

\section{1. はじめに}

生物の形成する社会はヒトから昆虫まで社会性の複雑 さは多様であるが, 共通している点は個体間相互作用に基 づいて社会の形成がボトムアップになされるという点で ある。つまり，身体・脳・環境のそれぞれの相互作用およ びその循環に基づいて社会形成がなされると考えること が出来る[1]. 特に昆虫脳は, 神経系全体でも約 $10^{6}$ 個の細 胞数で構成され，ヒトの脳における神経細胞数約 $10^{12}$ 個 に比べると非常に少ないにもかかわらず,優れた環境適応 能力を有する。このため生物の社会適応的な行動にヒント を得た生物模倣(バイオミメティクス)研究が行われてい る[2]。 また近年，生物の神経系での情報処理原理につい て議論が始められており[1], 生物の社会適応的な行動選 択を発現する神経系の動的な情報処理メカニズムについ ても研究され始めている[3].

一方で,一般的に複数ロボットシステムに期待されるこ とは, 単一のロボットでは達成困難な作業を行うことや作 業効率向上等であり,多様かつダイナミックに変化する環 境に適応するためのシステム制御手法に関する研究開発 が行われている。これらのうち，サブシステム間の相互作 用に基づいて秩序ある行動を発現させる自律分散システ ムや創発システムといった考え方・アプローチがある。こ れらの研究分野では生物の社会のようなロバストかつ柔 軟なシステムをいかに設計するかが課題となっている。そ こで, 本稿ではこれまでに我々が構築してきたクロコオロ ギの神経生理モデル[4]の有する個体間相互作用に基づい た行動選択機構の複数ロボットシステムへの応用につい て議論する.我々が対象としているクロコオロギの闘争行
動(図 1)は，飭やメスを巡る争いであり，縄張り争いとし ての特色が強いと考えられている。そのため複数ロボット システムとしては, 相互作用に基づいたボトムアップな作 業領域の分担を実現することが期待できる.

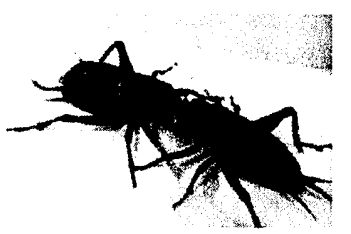

Fig.1 Cricket Fighting behavior

複数ロボット間の作業領域分担を行うことで効率化が 期待できる作業の一例として掃引作業がある.掃引作業に 関する従来研究の主流は, 環境情報が既知の場合における 経路計画を行うものである[5][6]. しかしながら，これら の研究ではオフラインによる経路計画等を行っているた め, 未知環境における掃引作業にそのまま適用することが 出来ない. そこで, クロコオロギの他個体との相互作用に よる行動選択の変化に着目し, 複数ロボットによる掃引作 業の動作アルゴリズムとしての応用を考える.

そこで, 本稿では未知環境を探索するような複数ロボッ トの典型的な作業の例である掃引作業に適用し, 計算機シ ミュレーションにより提案モデルがもたらす効果につい て考察を行う.

\section{2. クロコオロギの神経生理モデル}

ここで, 我々が研究を行ってきたクロコオロギの闘争行 動に関する神経生理モデルについて概説する。 


\section{1 クロコオロギの個体行動変容}

オスのクロコオロギは他のオス個体と遭遇し,オスフエ ロモンを感受すると闘争行動を発現することが知られて いる.この闘争行動はフェロモン感受により必ず発現する 行動であると考えられてきた．ところが最近の研究では, 闘争に負けた個体の内部状態(オクトパミン)のレベルは 低くなり 60 分程度の間, 他個体に対し逃避行動を示すこ とが報告されている[7].このような行動の切り替えは, 個体間相互作用の結果に基づいて可塑的に形成される適 㐫的行動選択と捉えることが出来る。

\section{2 クロコオロギの群行動変容}

クロコオロギは個体密度に応じて群行動を変化するこ とも報告されている[8]. 具体的に, 触角が他個体と常に 触れ合ってしまうような高密度環境 $(12 \times 9[\mathrm{~cm}])$ では各個 体は活発に行動しなくなる。一方で, 低密度環境 $(30 \times$ $22.5[\mathrm{~cm}])$ と呼んでいる広い環境では各個体は活発に行動 する。また，高密度と低密度の中間程度の密度 $(20 \times$ $15[\mathrm{~cm}])$ の場合, 一部の個体のみが活発となり, 残りの個 体を追い回すような状態が観察される。このことは環境密 度の変化に伴う相互作用頻度の変化によって適応的に行 動変容を実現していると考えることが出来る。

\section{3 クロコオロギ神経生理モデル}

我々はこれまでに上記の個体·群レベル双方のクロコオ ロギの行動変容を矛盾なく再現可能なモデル構築を行い, 妥当性を確認してきた[4]. 我々がこれまでに提案してき たモデルを図 2 に示す。

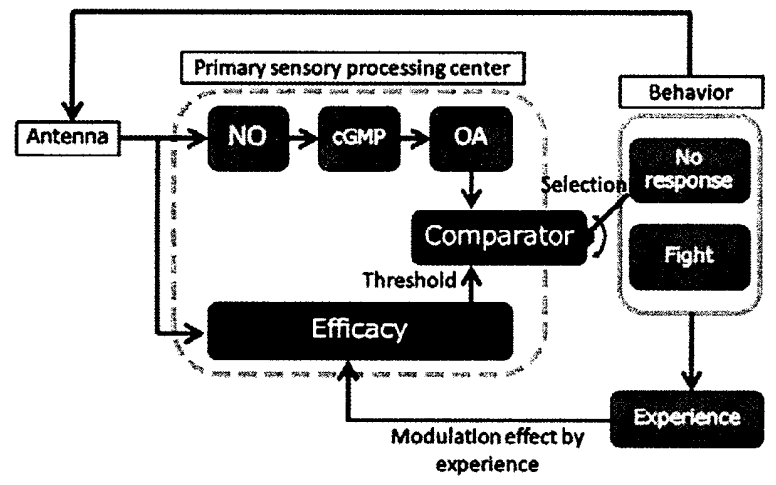

Fig.2 Proposed neurophysiologic model

このモデルではオクトパミン $(\mathrm{OA}) を$ 仮定した内部状態 と触角からの感覚入力感受性により行動選択が行われる ものである. 概念的には, 感覚入力感受性值が高い場合は NO/cGMP-OA システムが駆動して闘争行動か逃避行動 を選択し, 感覚入力感受性值が低い場合は無反応となる. これにより個体・群レベルの双方の適応行動を矛盾なく説 明可能となっている。.さらにシミュレーション実験から， 個体の発現する多様な行動の生成には触角からの感覚入 力感受性が重要な要素であることが示唆され, 感受性の効 果を持たせない個体は,クロコオロギの挙動を再現しない ことがこれまでの研究で分かっている。

以上のことより, 構築モデルは触角からの感覚入力感受 性を持たせることにより行動選択を調節する特徴を持ち, また，上述した通り，クロコオロギの闘争行動は他個体と の䋥張り争いのような特徴を持つことが示唆されている. これらのことから,クロコオロギの行動選択モデルにより 個体間相互作用に基づき協調的な作業領域の分担がボト ムアップに形成されることが期待できる.

\section{3. 䶂数ロボットによる掃引作業への適用}

ここでは提案モデルの掃引作業の作業時間, 移動効率に
ついて議論する.特に触角からの感覚入力感受性の有する 行動選択間值の評価基準を動的に変化させる特性につい て注目するため，以下の条件に設定した。

- 手法 1 (提案手法) :

ロボットの近傍 8 セグメントにセンシング領域を持ち, 他のロボットをセンシング領域内で検知した場合, 相互 作用に基づいた行動選択を行う。（図 2 : 左）

- 手法 2 (比較対象手法):

手法 1 のモデルから触角からの感覚入力感受性 (Efficacy)の要素を取り除いたモデルにより行動選択を 行う. (図 $2:$ 右)

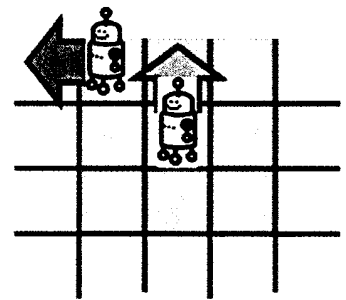

\section{Standard of Fighting}

Fighting : $O A \geq 0.5$

$n$ Efficacy $E \geq 1.0$

$\checkmark$ Efficacy $E<1.0$
Escape : $O A<0.5$

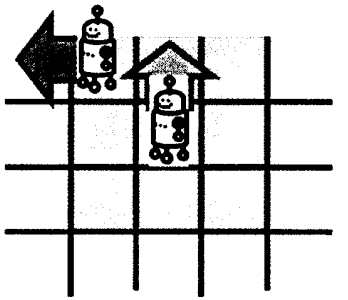

Standard of Fighting

Fighting : $O A \geq 0.5$

Escape : OA $<0.5$
Fig. 3 Behavior of the agent

(Left : Method 1, Right : Method 2)

以上の 2 種類の移動アルゴリズムを適用した場合の実 験結果を比較した。

実験の作業環境の設定は以下の通りとする。

・1 セグメントを $10 \times 10$ [pixel]で表現し，四辺を障害物で 囲まれている正方形の環境を想定

・環境サイズが $10 \times 10$ (高密度環境), $20 \times 20$ (中密度環境), $40 \times 40$ セグメント(低密度環境)の 3 種類の環境での作 業を比較

・試行回数は各環境サイズでそれぞれ 50 試行行う

・ロボットは $10 \times 10$ [pixel]で表現し, 1 ステップに 1 セグ メント移動することが可能

・環境に投入するロボット台数は 4 台

・環境を掃引し終えた時点で作業終了

上記の環境において各手法を適用した際の掃引終了ま での作業時間を図 4 に示す.

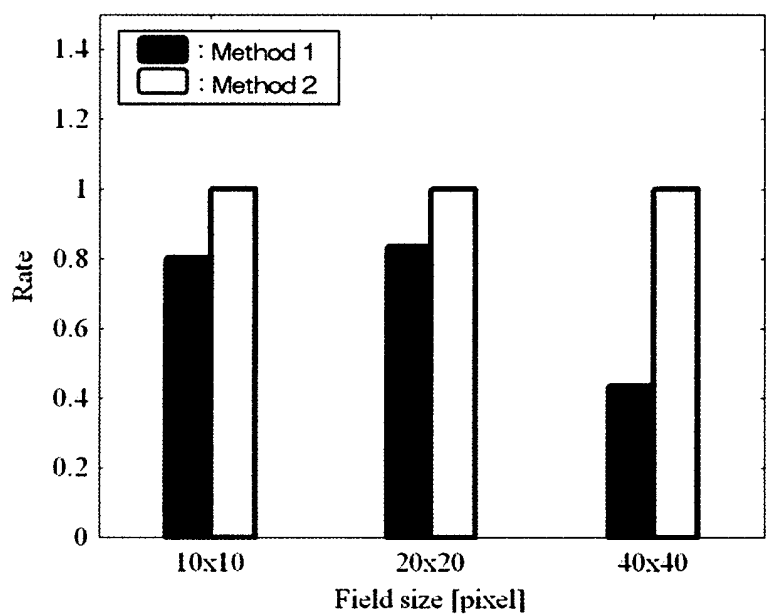

Fig.4 Comparison of the achievement rate of the sweeping 
図 4 では手法 2 の平均掃引ステップを基準として, 手 法 1 と手法 2 の作業達成時間の比率を表している.

実験結果より, 手法 1 の作業時間は手法 2 と比較し, 高密度環境では 80.4 [\%]，中密度環境では $83.7[\%]$, 低密 度環境では $43.4[\%]$ となり，作業時間が減少することが確 認できた。このことより，環境を変化させた場合の掃引作 業に拈いて触角からの感覚入力感受性が存在することで 効率が上がることがいえる。

引き続き,作業中のロボットの移動効率を比較したもの を図 5 に示す。ここで，ロボットの移動効率は評価関数 PI を用いて評価する.評価関数 PI は式(1)のように表す.

$$
\mathrm{PI}=\frac{\sum_{\mathrm{i}=1}^{\mathrm{n}} \mathrm{s}_{\mathrm{i}}}{\mathrm{n}} / \mathrm{T}
$$

$\mathrm{s}_{\mathrm{i}}$ は各試行においてロボットが探索した移動量を，Tは 掃引終了まで要したステップ数を, $\mathrm{n}$ は投入するロボット 台数をそれぞれ表す。式(1)ではロボットの単位時間当た りの平均移動距離を評価值とし，移動効率を表している.

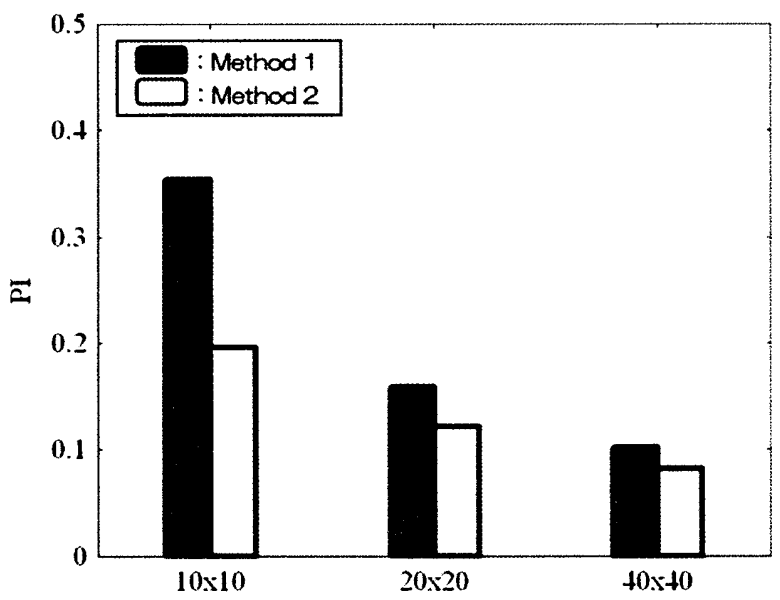

Field size [pixel]

Fig.5 Evaluation in each environment by evaluation function PI

図 5 より,手法 1 の各ロボットの移動は手法 2 の移動 効率と比較して高密度環境で $180.7[\%]$ ，中密度環境で 130.6[\%], 低密度環境で $125.6[\%]$ 高い評価值を得ており, 効率的に環境中を探索していることが分かる。これは，手 法 1 が相互作用に基づいて内部状態およびその評価基準 を動的に調節することで移動方向を決定したため環境に 応じた効率の良い移動が実現されたと考えることが出来 る.これにより掃引作業の移動効率という観点からも触角 からの感覚入力感受性を考慮することが重要であること が示唆された

\section{4. 提案モデルの移動特性についての考察}

3 節において，提案モデルに基づいた行動選択を行う口 ボットの方が作業効率の向上が確認出来た. 本節では, 提 案モデルの掃引面積を観察することで, 提案モデルの作業 効率について考察を行う.

ここで,提案モデルを用いて実験を行った際の各ロボッ トの掃引面積を表したものを図 6,7,8(図 6:高密度環境, 図 7：中密度環境，図 8：低密度環境)に示す。また，図で は投入した 4 台の各ロボットの実験結果をそれぞれ記載 している.図は掃引終了時間が平均的な值に近い時のもの をサンプルデータとして用いている. 図では各ロボットが 各セグメントを通過した回数を計数しており, 通過の度合 いに応じて色分けをしている，具体的には，通過回数が 0 回の時には青, 1 回の時には水色, 2 9 回の時には黄色,
10 回以上の時には赤と色を付けている。

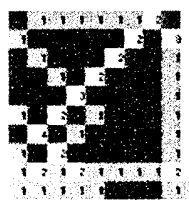

Robot A

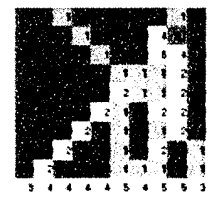

Robot B

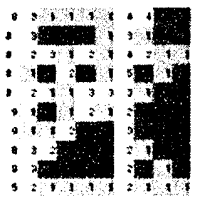

Robot C

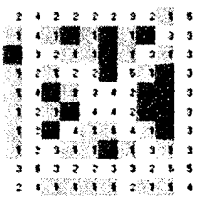

Robot D
Fig. 6 Sweep area in high density $(10 \times 10$ [pixel] $)$

高密度環境(図 6)では Robot A, Robot B のロボットは 環境中をほとんど掃引せずに作業を終了していることが 確認できる．また，Robot C は環境の右半分をほとんど掃 引していないことが確認できる。このことより提案モデル は相互作用によって個々が行動する領域を分ける結果と なっており，効率の良い作業を実現したと考えられる。

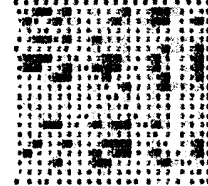

Robot A

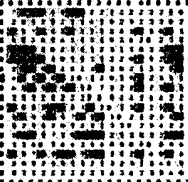

Robot B

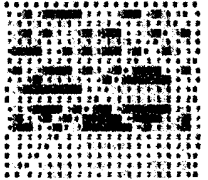

Robot C

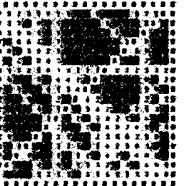

Robot D
Fig. 7 Sweep area in middle density $(20 \times 20$ [pixel] $)$

中密度環境(図 7)でも同様に各ロボットは環境中で掃引せ ずに終える領域が存在することが確認出来るため, 相互作 用によって効率の良い作業を実現したと考えられる。

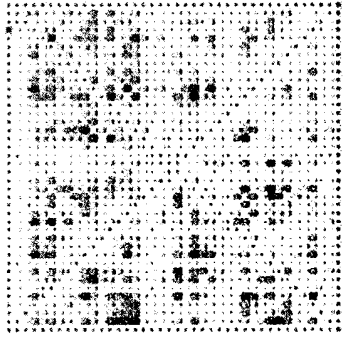

Robot A

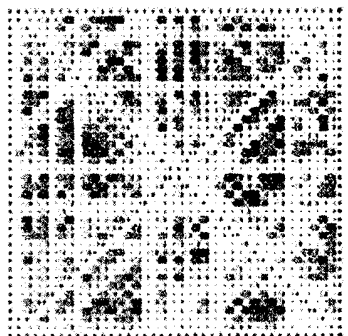

Robot C

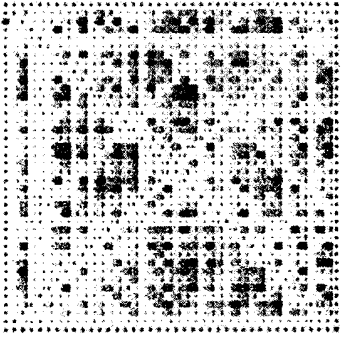

Robot B

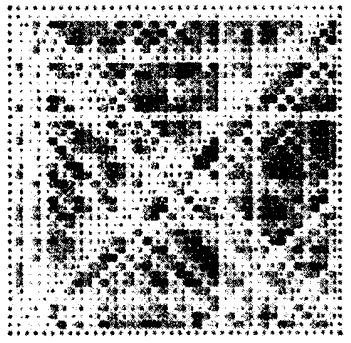

Robot D
Fig. 8 Sweep area in low density $(40 \times 40[$ pixel] $)$

低密度環境(図 8)でも同様に，各ロボットにおいて掃引 していない領域が存在し, 個々が行動する領域を分ける結 果となった。

以上の結果と 3 節で述べた評価関数 PI による評価をみ ると, 高密度環境での作業効率が特に向上する.これは他 個体と相互作用する機会が多い方がクロコオロギの行動 の特性をより行動に反映させることが可能になっている と考える。つまり他のロボットとの間隔が密である環境や 状況に関して, ロボット間の相互作用により環境に適応し た行動選択を実現可能であることが確認された。 


\section{5. おわりに}

本稿ではクロコオロギの神経生理モデルを用いた複数 ロボットシステムの動作生成について, 特に掃引作業を例 に工学的な観点で議論した. 実験からは他個体との相互作 用による行動選択の変化によって環境中を効率よく掃引 することが出来ることを確認した。特に，他のロボットと 相互作用寸る機会の多い環境に扔いては触角からの感覚 入力感受性を持たないモデルと比較して高い有用性を持 つことが確認できた。

今後は今回用いた他の比較対象を用いて提案手法の有 用性を詳細に検討していく.

\section{謝辞}

本研究の一部は, 文部科学省科学研究費補助金特定領域 研究「身体・脳・環境の相互作用に上る適応的運動機能の 発現 一移動知の構成論的理解一」によって行われた。

\section{参考文献}

［1］高草木薰 他:"移動知：行動からの知能理解一構成論的観 点と生物学的観点から”. 計測と制御, Vol.44, No. 9, pp. 580-589, 2005.
[2] 渡辺 桂吾 他, バイオミメティックマシンとロボット： ファジィ推論技法による接近(く小特集>制御工学への知能 科学からの接近) 日本シミュレーション学会 Vol.26(1) (2007) pp.26-32

[3] 淺間 - 他, 移動知と社会適応, 計測と制御 Vol.46, No.12 (2007) pp.885-886

[4] 藤井喬 他: “クロコオロギの行動選択機構のモデリングに 関する研究 一喧嘩行動実験による神経機構モデルの考察 -", 第14回ロボティクスシンポジア講演予稿集, pp.35-41, 2009.

[5] 倉林大輔 他: “掃引作業における移動ロボット群の行動計 面”, 日本ロボット学会誌, Vol.16, No.2, pp.181-188, 1998.

[6] 深澤祐介，他：“格子点配置を用いた自律移動ロボットに よる環境掃引経路計画”，計測自動制御学会論文集, 39, 11 , p.1054/1060, 2003.

[7] M.Sakura, et al.: "Fighting experiences modulate aggressive and avoidance behaviors in crickets against male cuticular substances.", The 2nd International Symposium on Mobiligence, pp243-246, 2007.

[8] 足利昌俊 他:“コオロギ集団における多様的振る舞いのモ デル化”，第18回自律分散システム・シンポジウム講演予稿 集, pp.189-194, 2006 